\title{
Is Remission a Valid Target for Gout?
}
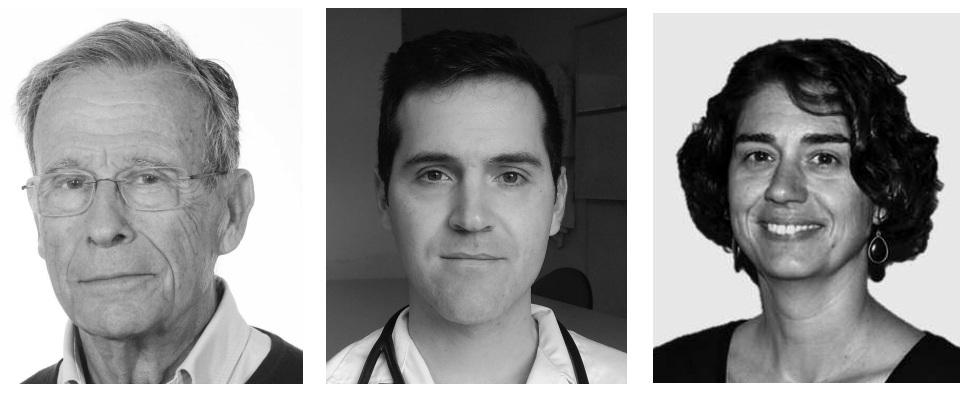

The ideal aim of treatment in any disease is to achieve a cure. This is feasible in most infectious diseases, but in many chronic diseases - such as rheumatoid arthritis (RA), systemic lupus erythematosus (SLE), or psoriasis - a cure is not yet possible. Available treatments can only hope to decrease disease activity, leading to the disappearance of symptoms and avoiding or minimizing its progression and consequences. This state has received the name of remission; its definition in the Merriam-Webster Medical Dictionary ${ }^{1}$ is "a state or period during which the symptoms of a disease are abated." Remission and cure are, thus, different aims. In the report by Alvarado-de la Barrera, et $a l^{2}$, in this issue of The Journal, recently developed Preliminary Criteria for the Remission of Gout - which have not undergone further validation - have been applied to patients with gout attending a tertiary center in Mexico. The characteristics of these patients have been described previously ${ }^{3}$ as coming from a low socioeconomic background and being particularly noncompliant, having poorly managed, very severe gout, and treating their symptoms with self-prescribed glucocorticoid monotherapy ${ }^{4}$, a therapy associated to the early appearance of tophi ${ }^{5,6}$. However, is the concept of remission applicable to gout?

In gout, current imaging techniques - particularly sonography and dual-energy computed tomography - have increased our understanding of the disease. They have shown the monosodium urate (MSU) crystal deposits in different sites and allow the monitoring of their decrease and confirmation of their disappearance after appropriate serum urate (SU) lowering treatment ${ }^{7,8}$. Disappearance of MSU crystals from synovial fluid of index joints has also been proven ${ }^{9}$. Therefore, gout is now considered curable ${ }^{10}$.

Standards of gout management are known to be poor ${ }^{11}$, and the term remission might mislead some readers into believing that eliminating symptoms is an acceptable aim for gout treatment. Although the definition of gout remission includes a target $\mathrm{SU}$ of $<6 \mathrm{mg} / \mathrm{dl}$, a value at which MSU crystal deposits are already dissolving, current guidelines recommend lower targets ${ }^{12}$ for different subgroups of gout to achieve faster crystal elimination, especially in patients with severe gout such as those recruited in the current paper. Remission criteria fail to take this into account. Additionally, to achieve remission, tophi must not be present. If both these criteria are met (target SU and disappearance of previously present tophi), then the patient is on the way toward crystal dissolution, and therefore a cure. However, that point might not have been reached yet. Finally, remission requires that 3 symptom-based criteria must be achieved: no flares, mild pain, and good patient global assessments. These can be achieved through other management approaches, such as flare prophylaxis with colchicine, even in the absence of urate-lowering drugs. Remission is a state that most patients will go through on their way to complete crystal dissolution, but some patients with severe gout, even when "cured," could maintain high pain scores due to irreversible gout-related joint damage, thereby never achieving remission. Information on which remission criteria were not met in the severe gout group would have perhaps given further insight on this reality. It would be unwise for the concept of remission to become a widespread aim in the clinical management of gout and should be kept for clinical trials for which the preliminary gout remission criteria were designed. Unfortunately, criteria are frequently used for aims different from those for which they were developed. The classification criteria for RA or SLE are commonly, albeit inappropriately, used for diagnosis, and the (allowed) continued use of the 1977 "preliminary criteria for the classification of the acute arthritis of primary gout" 13 in clinical trials, despite its proven uncertainties ${ }^{14,15}$, is to be noted.

Perhaps, for the type of patients seen at the Hospital General de México Eduardo Liceaga and similar patient cohorts and circumstances, the concept of remission may be useful. These patients are of a low socioeconomic background and live in areas of Mexico City with its particular

See Remission and gout, page 132 
health culture. Gout is frequently familial because of genetic or common familial lifestyles, often starts at a young age, and may become tophaceous early, likely because of the continued use of corticosteroids. Patients self-treat with oral or parenteral glucocorticoids to carry on with their daily activities and only seek hospital care if they are irresponsive to this self-treatment. Commonly, they have received glucocorticoids for a prolonged time. Having conversed several times with Dr. Vazquez-Mellado about her patients and attended her clinics, I note 2 particularly relevant comments of hers: that corticosteroids are the cheapest freely available medication for gout in Mexico (and other countries; allopurinol being more expensive), and that after the symptoms are properly controlled and they feel able to return to work, patients are lost to followup. Perhaps some of the high number of patients lost to followup could have fulfilled the preliminary criteria for remission. Therefore, in this context and for this patient population, the concept of remission, describing a modest but acceptable disease state, might be informative.

Finally, these patients with such severe, untreated advanced gout (and others similar at other sites ${ }^{16}$ ) remind us of the times when gout had no effective treatment. Before glucocorticoids, only colchicine and aspirin were available and only dietary modifications could be recommended to attempt to reduce SU levels. In those times, gout was an incurable, terribly invalidating disease for many patients. As in other rheumatic diseases, glucocorticoids brought a miraculous remedy for gout flares ${ }^{17}$, and its use sometimes needed to be continuous when gout manifestations made it necessary, showing later the inadequacy of this approach. Thankfully, those times are past in many countries and urate-lowering therapies are widely available, making total crystal dissolution and cure achievable. Worldwide inequity is patent in many rheumatic diseases ${ }^{18}$ and has now become blatantly clear in gout as well.

\section{ELISEO PASCUAL (D), MD, $\mathrm{PhD}$,}

Emeritus Professor, Departamento de Medicina Clínica Universidad Miguel Hernández, and Instituto de Investigación Sanitaria y Biomédica de Alicante (ISABIAL); MARIANO ANDRÉS (D), MD, PhD, Sección de Reumatología, Hospital General Universitario de Alicante, Departamento de Medicina Clínica, Universidad Miguel Hernández, and ISABIAL;

FRANCISCA SIVERA (i), $\mathrm{MD}, \mathrm{PhD}$,

Sección de Reumatología, Hospital General Universitario de Elda, Alicante, Spain.

Address correspondence to Prof. E. Pascual, Universidad Miguel Hernandez, Carretera Nacional 332 s/n, 03550, San Juan de Alicante, Alicante, Spain.E-mail: pascual_eli@gva.es

\section{REFERENCES}

1. Merriam-Webster Medical Dictionary. [Internet. Accessed May 7, 2019.] Available from: www.merriamwebster.com/dictionary/remission\#medicalDictionary

2. Alvarado-de la Barrera C, López-López CO, Álvarez-Hernández E, Peláez-Ballestas I, Gómez-Ruiz C, Burgos-Vargas R, et al. Are target urate and remission possible in severe gout? A 5-year cohort study. J Rheumatol 2020;47:132-9.

3. Vázquez-Mellado J, Cruz J, Guzmán S, Casasola-Vargas J, Lino L, Burgos-Vargas R. Severe tophaceous gout. Characterization of low socioeconomic level patients from México. Clin Exp Rheumatol 2006;24:233-8.

4. Alvarez-Hernández E, Vázquez-Mellado J, Casasola-Vargas JC, Moctezuma-Ríos JF, García-García C, Medrano-Ramírez G, et al. The use of glucocorticoids by rheumatologic patients before attending a specialized department in México. J Clin Rheumatol 2008;14:148-52.

5. Vázquez-Mellado J, Cuan A, Magaña M, Pineda C, Cazarín J, Pacheco-Tena $\mathrm{C}$, et al. Intradermal tophi in gout: a case-control study. J Rheumatol 1999;26:136-40.

6. Raso AA, Sto Niño OV, Li-Yu J. Does prolonged systemic glucocorticoid use increase risk of tophus formation among gouty arthritis patients? Int J Rheum Dis 2009;12:243-9.

7. Araujo EG, Bayat S, Petsch C, Englbrecht M, Faustini F, Kleyer A, et al. Tophus resolution with pegloticase: a prospective dual-energy CT study. RMD Open 2015;1:e000075.

8. Peiteado D, Villalba A, Martín-Mola E, Balsa A, De Miguel E. Ultrasound sensitivity to changes in gout: a longitudinal study after two years of treatment. Clin Exp Rheumatol 2017;35:746-51.

9. Pascual E, Sivera F. The time required for disappearance of urate crystals from synovial fluid after successful hypouricemic treatment relates to the duration of gout. Ann Rheum Dis 2007;66:1056-8.

10. Richette P, Doherty M, Pascual E, Barskova V, Becce F, Castañeda-Sanabria J, et al. 2016 updated EULAR evidence-based recommendations for the management of gout. Ann Rheum Dis 2017;76:29-42.

11. Roddy E, Packham J, Obrenovic K, Rivett A, Ledingham JM. Management of gout by UK rheumatologists: a British Society for Rheumatology national audit. Rheumatology 2018;57:826-30.

12. Kiltz U, Smolen J, Bardin T, Cohen Solal A, Dalbeth N, Doherty M, et al. Treat-to-target (T2T) recommendations for gout. Ann Rheum Dis 2017;76:632-8.

13. Wallace SL, Robinson H, Masi AT, Decker JL, McCarty DJ, Yu TF. Preliminary criteria for the classification of the acute arthritis of primary gout. Arthritis Rheum 1977;20:895-900.

14. Malik A, Schumacher HR, Dinnella JE, Clayburne GM. Clinical diagnostic criteria for gout: comparison with the gold standard of synovial fluid crystal analysis. J Clin Rheumatol 2009;15:22-4.

15. Janssens HJ, Janssen M, van de Lisdonk EH, Fransen J, van Riel PL, van Weel C. Limited validity of the American College of Rheumatology criteria for classifying patients with gout in primary care. Ann Rheum Dis 2010;69:1255-6.

16. Padang C, Muirden KD, Schumacher HR, Darmawan J, Nasution AR. Characteristics of chronic gout in Northern Sulawesi, Indonesia. J Rheumatol 2006;33:1813-7.

17. Friedlander RD. Cortisone as an adjunct in the therapy of acute gout. J Am Med Assoc 1951;145:11-4.

18. Putrik P, Ramiro S, Kvien TK, Sokka T, Pavlova M, Uhlig T, et al; Working Group 'Equity in access to treatment of rheumatoid arthritis in Europe'. Inequities in access to biologic and synthetic DMARDs across 46 European countries. Ann Rheum Dis 2014;73:198-206.

J Rheumatol 2020;47:4-5; doi:10.3899/jrheum.190386

Personal non-commercial use only. The Journal of Rheumatology Copyright $\odot$ 2019. All rights reserved. 